\title{
Molecular Analysis of the X11-mLin-2/CASK Complex in Brain
}

\author{
Jean-Paul Borg, ${ }^{1}$ Manuel O. Lõpez-Figueroa, ${ }^{4}$ Mylène de Taddèo-Borg, ${ }^{2}$ Dallas E. Kroon, ${ }^{1}$ R. Scott Turner, ${ }^{3}$ \\ Stanley J. Watson, ${ }^{4}$ and Ben Margolis ${ }^{1,2}$
}

${ }^{1}$ Howard Hughes Medical Institute, Departments of 2 Internal Medicine and ${ }^{3}$ Neurology and Biological Chemistry, ${ }^{4}$ Mental Health Research Institute, University of Michigan Medical Center, Ann Arbor, Michigan 48109

\begin{abstract}
A heterotrimeric complex containing Lin-10/X11 $\alpha$, Lin-2/CASK, and Lin-7 is evolutionarily conserved from worms to mammals. In Caenorhabditis elegans, it localizes Let-23, a receptor tyrosine kinase, to the basolateral side of vulval epithelium, a step crucial for proper vulva development. In mammals, the complex may also participate in receptor targeting in neurons. Accordingly, phosphotyrosine binding (PTB) and postsynaptic density95/Discs large/Zona Occludens-1 domains found in X11 $\alpha$ and mLin-2/CASK bind to cell-surface proteins, including amyloid precursor protein, neurexins, and syndecans. In this paper, we have further analyzed the $\mathrm{X} 11 \alpha-\mathrm{mLin}-2 / \mathrm{CASK}$ association that is mediated by a novel protein-protein interaction. We show that the mLin-2/CASK calmodulin kinase II (CKII) domain di-
\end{abstract}

rectly binds to a 63 amino acids peptide located between the Munc-18-1 binding site and the PTB domain in $\mathrm{X} 11 \alpha . \mathrm{Ca}^{2+} /$ calmodulin association with mLin-2/CASK does not modify the $\mathrm{X} 11 \alpha-\mathrm{mLin}-2$ interaction. A region containing the $\mathrm{mLin}-2 / \mathrm{CASK}$ guanylate kinase domain also interacts with $\mathrm{X} 11 \alpha$ but with a lower affinity than the CKII domain. Immunostaining of $\mathrm{X} 11 \alpha$ in the brain shows that the protein is expressed in areas shown previously to be positive for mLin-2/CASK staining. Together, our data demonstrate that the $\mathrm{X} 11 \alpha-\mathrm{mLin}-2$ complex contacts many partners, creating a macrocomplex suitable for receptor targeting at the neuronal plasma membrane.

Key words: PDZ; PTB; X11; mLin-2/CASK; CaM kinase; receptor localization
Protein-protein interactions govern signal transduction networks and localization of proteins in the cells. They are mediated by a growing number of protein modules that bind peptide and lipid targets (Pawson and Scott, 1997). Phosphotyrosine binding (PTB) domains found in Shc and insulin receptor substrate-1 bind to tyrosine phosphorylated peptides and play an important role in tyrosine kinase signaling, whereas analogous domains identified in X11, Numb, and Fe65 prefer unmodified peptides (Borg and Margolis, 1998). Postsynaptic density-95/Discs large/ Zona Occludens-1 (PDZ) domains bind C-terminal peptides and participate in receptor localization (Fanning and Anderson, 1997). For example, the well characterized postsynaptic density-95 (PSD-95) protein engages interaction with NMDA receptor and $\mathrm{K}^{+}$channels, a step important for their clustering at the plasma membrane (Kim et al., 1995; Kornau et al., 1995).

We recently described the X11 protein family containing one PTB and two PDZ domains. The X11 PTB domain interacts with a tyrosine-based peptide found in amyloid precursor protein (APP), a protein important for Alzheimer's disease pathogenesis (Borg et al., 1996; McLoughlin and Miller, 1996; Zhang et al., 1997). This interaction allows X11 proteins to slow the processing of APP to $\mathrm{A} \beta$, a peptide found in the plaques of patients with Alzheimer's disease (Borg et al., 1998b). The X11 family comprises three members: $\mathrm{X} 11 \alpha, \mathrm{X} 11 \beta$, and $\mathrm{X} 11 \gamma$, also called Munc-

\footnotetext{
Received Sept. 21, 1998; revised Nov. 23, 1998; accepted Dec. 1, 1998.

This study was supported by National Institute of Mental Health Program Project MH 42251 and the Pritzker Network (M.O.L and S.J.W.). B.M. is an investigator of the Howard Hughes Medical Institute. We thank Dr. Lawrence Mathews for the purified calmodulin and anti-calmodulin antibody. Anti-giantin monoclonal antibody was kindly provided by Dr. Hans-Peter Hausi.

Correspondence should be addressed to Dr. Ben Margolis, Howard Hughes Medical Institute, University of Michigan Medical Center, Room 4570, MSRB II, 1150 West Medical Center Drive, Ann Arbor, MI 48109-0650.

Drs. Borg and López-Figueroa contributed equally to this work.

Copyright (C) 1999 Society for Neuroscience $\quad 0270-6474 / 99 / 191307-10 \$ 05.00 / 0$
}

interacting proteins (Mints) (Okamoto and Sudhof, 1997; Borg et al., 1998a). Although X11 $\alpha$ and X11 $\beta$ are strictly neuronal, X11 $\gamma$ is expressed in all tissues (Duclos et al., 1993; Borg et al., 1998b). $\mathrm{X} 11 \alpha$ participates in a brain-specific heterotrimeric complex containing two other PDZ domain proteins, mLin-2/CASK and mLin-7 (Borg et al., 1998a; Butz et al., 1998). The mLin-2/CASK protein also contains a calmodulin kinase II (CKII), an SH3, and a guanylate kinase (GK) domain and is related to other membrane associated guanylate kinase (MAGUK) proteins (Hata et al., 1996; Hoskins et al., 1996). In C. elegans, mutations of lin-10, lin-2, and lin-7 genes, representing the respective homologs of $X 11 \alpha$, mLin-2/CASK, and mlin-7 in mammals, abrogate the basolateral localization of Let-23 in vulval epithelium and preclude subsequent activation by its ligand (Hoskins et al., 1996; Simske et al., 1996; Kaech et al., 1998). Mislocalization of Let-23 leads to a vulvaless phenotype equivalent to mutations affecting receptor activation.

We and others have demonstrated that the $\mathrm{N}$ terminus of $\mathrm{X} 11 \alpha$ binds to mLin-2/CASK and that this interaction is required for the in vivo X11 $\alpha-$ mLin-2 interaction (Borg et al., 1998a; Butz et al., 1998; Kaech et al., 1998). Here, we further delineate this binding site to a 63 amino acids peptide in $\mathrm{X} 11 \alpha$. The mLin-2/ CASK CKII domain strongly interacts with this peptide in precipitation and overlay assays. Deletions of the CKII domain indicate that the integrity of the domain is required for this interaction. The calmodulin binding site located $\mathrm{C}$-terminal to the mLin-2/CASK CKII domain is not required for binding to $\mathrm{X} 11 \alpha$, and binding of calmodulin does not interfere with the $\mathrm{X} 11 \alpha-$ mLin-2/CASK interaction. We also demonstrate that the mLin-2/CASK GK domain and its flanking sequences interact with $\mathrm{X} 11 \alpha$ in vitro. In situ hybridization and immunostaining show that $\mathrm{X} 11 \alpha$ has a somatodendritic pattern in neurons and is particularly expressed in olfactory bulb, cerebellum, cortex, and 
several brainstem nuclei. Cell-surface proteins, such as neurexins, syndecans, and APP, interact with the X11 $\alpha$-mLin-2/CASK complex through PTB and PDZ domain interactions (Borg et al., 1996; Hata et al., 1996; Cohen et al., 1998; Hsueh et al., 1998). Additional binding of mLin-7, Munc-18-1-Syntaxin, and calmodulin generates a neuronal multiprotein complex, which we predict will be involved in receptor localization.

\section{MATERIALS AND METHODS}

Antibodies. Anti-Myc 9E10 (Oncogene Research Products, Cambridge, MA) monoclonal antibody was used for immunoprecipitation and immunoblotting. Polyclonal anti-mLin-2/CASK and anti-X11 antibodies were described previously (Borg et al., 1998a). Anti-PSD-95 and anticalmodulin monoclonal antibodies were from Upstate Biotechnology (Lake Placid, NY). Anti-T7 monoclonal antibody was from Novagen (Madison, WI). Anti-Syntaxin monoclonal antibody was from Sigma (St. Louis, MO). Anti-Munc-18-1 and anti-mLin-2/CASK monoclonal antibodies were from Transduction Laboratories (Lexington, KY). Avidinbiotin blocking kit, biotinylated goat anti-rabbit IgG, and streptavidin biotinylated horseradish peroxidase complex were purchased from Vector Laboratories (Burlingame, CA).

$D N A$ constructs. Full-length $X 11 \alpha, X 11 \beta$, and $X 11 \gamma$ cDNAs have been described elsewhere (Borg et al., 1998a,b). Human lin-2 cDNA assembled from expressed sequence tags (identical to GenBank accession number AF035582) (Borg et al., 1998a) was used as a template to create different constructs, allowing expression of glutathione $S$-transferase (GST) fusion proteins. The RK5-myc vector was used to express X11 $\alpha$ and mLin-2/ CASK fused to the myc epitope (Borg et al., 1996). All constructs were sequenced using Sequenase version 2.0 (Amersham, Cleveland, $\mathrm{OH}$ ).

Cell culture. Human embryonic kidney 293 and A-172 cells were grown in DMEM (Life Technologies, Grand Island, NY) containing $100 \mathrm{U} / \mathrm{ml}$ penicillin and $100 \mu \mathrm{g} / \mathrm{ml}$ streptomycin sulfate, supplemented with $10 \%$ fetal calf serum (FCS). NT2 cells were maintained in DMEM-F-12 medium containing $100 \mathrm{U} / \mathrm{ml}$ penicillin and $100 \mu \mathrm{g} / \mathrm{ml}$ streptomycin sulfate, supplemented with $10 \%$ FCS.

Immunohistochemistry. Five male Sprague Dawley rats from Charles River Laboratories (Wilmington, MA), weighing 250-325 gm, were used in this study. The rats were anesthetized with sodium pentobarbital (50 mg/kg, i.p.) (Butler, Columbus, $\mathrm{OH}$ ) and perfused transcardially with $0.1 \mathrm{M}$ phosphate buffer (PB), pH 7.6, containing 15,000 U/1 heparin, followed by $4 \%$ paraformaldehyde in $0.1 \mathrm{M} \mathrm{PB}$. The brains were removed, post-fixed for $1 \mathrm{hr}$ in the same fixative at $4^{\circ} \mathrm{C}$, and then cryoprotected

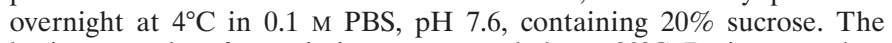
brains were then frozen in isopentane cooled to $-80^{\circ} \mathrm{C}$. Brains were then sectioned on a Bright-Hacker cryostat, and the $40-\mu \mathrm{m}$-thick coronal sections were kept in antifreeze solution at $-20^{\circ} \mathrm{C}$ until processed for immunohistochemistry.

Immunohistochemistry was performed as described previously, with slight modifications (Lõpez-Figueroa et al., 1996). The free-floating sections were washed three times for 10 min each in PBS and incubated in $0.3 \% \mathrm{H}_{2} \mathrm{O}_{2}$ in methanol for $10 \mathrm{~min}$ at room temperature for quenching of the endogenous peroxidase activity. The sections were then washed three times for $10 \mathrm{~min}$ each in PBS. To reduce nonspecific background, sections were incubated in avidin-biotin blocking kit for $10 \mathrm{~min}$, followed by incubation in a solution of $5 \%$ normal goat serum, $0.1 \%$ bovine serum albumin (BSA), and $0.3 \%$ Triton X-100 (TX) in PBS for $20 \mathrm{~min}$. Sections were incubated with the specific antisera overnight at $4^{\circ} \mathrm{C}$ (polyclonal rabbit anti-X11 antibody used at 1:650) diluted in the previous solution. The sections were then rinsed three times for $10 \mathrm{~min}$ each in $0.1 \%$ TX in PBS, followed by incubation in biotinylated goat antirabbit IgG diluted 1:1000 in $0.1 \%$ TX in PBS for $1 \mathrm{hr}$ at room temperature. After washing three times for 10 min each in PBS, the sections were incubated with streptavidin biotinylated horseradish peroxidase complex diluted 1:1000 in PBS for $1 \mathrm{hr}$ at room temperature. The sections were then washed with PBS three times for $10 \mathrm{~min}$ each and developed with a solution of $0.05 \%$ diaminobenzidine, $0.006 \%$ nickel ammonium sulfate, and $0.001 \% \mathrm{H}_{2} \mathrm{O}_{2}$ in $0.1 \mathrm{M}$ sodium acetate. The sections were then washed twice in PBS, mounted, air dried, and coverslipped by use of Permount as mounting medium. Staining specificity was assessed with incubation of parallel sections in preincubated antiserum with its corresponding antigen. Images were captured using an Axiophot microscope (Zeiss, Oberkochen, Germany) and camera (DXC-970; Sony, Tokyo, Japan). In situ hybridization. Four rats were killed by rapid decapitation, and their brains were removed and frozen in isopentane cooled to $-80^{\circ} \mathrm{C}$. Brains were then sectioned on a cryostat, and the $15-\mu \mathrm{m}$-thick coronal sections, mounted onto polylysine-coated slides, were kept at $-80^{\circ} \mathrm{C}$ until processed for in situ hybridization. Riboprobes encoding the human $\mathrm{X} 11 \alpha \mathrm{N}$ terminus were used in this study. Antisense probes were transcribed from the T3 promoter using T3 RNA polymerase. The probe was labeled with $\left.{ }^{35} \mathrm{~S}\right] \mathrm{dUTP}$ and $\left[{ }^{35} \mathrm{~S}\right] \mathrm{dCTP}$ as described previously (Lõpez-Figueroa et al., 1998). The linearized plasmid was incubated for $2 \mathrm{hr}$ at $37^{\circ} \mathrm{C}$ in a solution containing $5 \times$ transcription buffer, $\left[{ }^{35} \mathrm{~S}\right] \mathrm{dUTP}$ and $\left[{ }^{35} \mathrm{~S}\right] \mathrm{dCTP}, 150 \mu \mathrm{M}$ dNTPs, $12.5 \mathrm{~mm}$ dithiothreitol, $20 \mathrm{U}$ of RNase inhibitor, and $6 \mathrm{U}$ of the corresponding RNA polymerase. The labeled probe was then separated in a Sephadex G50/50 column.

Tissue sections were then processed for in situ hybridization histochemistry. The sections were fixed in $4 \%$ paraformaldehyde for $1 \mathrm{hr}$, followed by three washes in $2 \times \mathrm{SSC}(1 \times \mathrm{SSC}$ is $150 \mathrm{~mm} \mathrm{NaCl}$ and $15 \mathrm{~mm}$ sodium citrate). The sections were then placed in a solution containing acetic anhydride $(0.25 \%)$ in triethanolamine $(0.1 \mathrm{M}, \mathrm{pH} 8.0)$ for $10 \mathrm{~min}$ at room temperature, rinsed in distilled water (DW), and dehydrated through graded series of alcohol. After air drying, the sections were hybridized with the corresponding ${ }^{35} \mathrm{~S}$-labeled cRNA probe in a hybridization buffer (containing 50\% formamide, $10 \%$ dextran sulfate, $3 \times$ SSC, $50 \mathrm{~mm}$ sodium phosphate buffer, $\mathrm{pH} 7.4,1 \times$ Denhardt's solution, 0.1 $\mathrm{mg} / \mathrm{ml}$ yeast tRNA, and $10 \mathrm{~mm}$ dithiothreitol) to yield $10^{6} \mathrm{dpm} / 35 \mu \mathrm{l}$. The sections were coverslipped and placed inside a humidified box overnight at $55^{\circ} \mathrm{C}$. After hybridization, the coverslips were removed, and the sections were rinsed and washed twice in $2 \times$ SSC for 5 min each and then incubated for $1 \mathrm{hr}$ in RNase $(200 \mu \mathrm{g} / \mathrm{ml}$ in Tris buffer containing 0.5 $\mathrm{M} \mathrm{NaCl}, \mathrm{pH} 8.0$ ) at $37^{\circ} \mathrm{C}$. The sections were washed in increasingly stringent solutions of $2 \times, 1 \times$, and $0.5 \times$ SSC for $5 \mathrm{~min}$ each, followed by incubation for $1 \mathrm{hr}$ in $0.1 \times \mathrm{SSC}$ at $65^{\circ} \mathrm{C}$. After rinsing in DW, the sections were dehydrated through graded alcohols, air dried, and exposed to a Kodak XAR film (Eastman Kodak, Rochester, NY) for 5-7 d. Finally, the sections were dipped into photographic emulsion (Kodak NTB-2), exposed for 13-17 d, developed in Kodak D-19 developer (2 min), fixed (3 min), and counter-stained with cresyl violet. Sections pretreated for 1 hr with RNase $(200 \mu \mathrm{g} / \mathrm{ml})$ or treated with sense riboprobes from the same plasmid insert were used as controls.

Immunostaining of NT2 cells. Differentiated NT2 cells were plated on acid-treated coverslips coated with poly-D-lysine (Sigma) and Matrigel (Collaborative Research, Bedford, MA). After fixation with PBS-4\% paraformaldehyde, cells were washed with PBS-10 mM glycine and permeabilized with PBS- $0.1 \%$ TX. After blocking for $1 \mathrm{hr}$ in goat serum, coverslips were incubated with antibodies diluted in PBS- $2 \%$ goat serum in a humidified chamber for $1 \mathrm{hr}$ (affinity-purified anti-X11 at 1:500, anti-mLin-2/CASK at 1:125, anti-giantin at 1:1000, and $6 \mathrm{E} 10$ anti-APP at 1:40). All secondary antibodies coupled to FITC or Cy3 (Sigma) were diluted at 1:200 in PBS-2\% goat serum. Confocal analysis of immunostaining was performed on a Noran confocal laser scanning imaging system (Noran Instruments, Middleton, WI) with a Nikon Diaphot 200 inverted microscope at the Morphology and Image Analysis Core of the University of Michigan Diabetes Research and Training Center.

Protein procedures. Cells were washed twice with cold PBS and lysed in lysis buffer (50 mu HEPES, pH 7.5, 10\% glycerol, $150 \mathrm{~mm} \mathrm{NaCl}, 1 \% \mathrm{TX}$, $1.5 \mathrm{mM} \mathrm{MgCl}_{2}$, and $1 \mathrm{~mm}$ EGTA) supplemented with $1 \mathrm{~mm}$ phenylmethylsulfonyl fluoride, $10 \mu \mathrm{g} / \mathrm{ml}$ aprotinin, and $10 \mu \mathrm{g} / \mathrm{ml}$ leupeptin. After centrifugation at $16,000 \times g$ for $20 \mathrm{~min}$, lysate protein content was normalized using the Bio-Rad (Hercules, CA) protein assay kit. Mouse brain proteins were extracted after a similar procedure. For immunoprecipitation, lysates were incubated with antibodies overnight at $4^{\circ} \mathrm{C}$. Protein A-agarose was added, and immune complexes bound to beads were recovered after $1 \mathrm{hr}$, washed three times with buffer (containing $50 \mathrm{~mm}$ HEPES, pH 7.5, $10 \%$ glycerol, $150 \mathrm{~mm} \mathrm{NaCl}$, and $0.1 \% \mathrm{TX}$ ), boiled in $1 \times$ sample buffer, and separated by SDS-PAGE. Transfer and immunoblotting on nitrocellulose using HRP protein A or HRP anti-mouse antibody chemiluminescence method were performed as described previously (Borg et al., 1996). For overlay assays, the membrane was incubated $2 \mathrm{hr}$ at room temperature with soluble His-tagged or GST fusion proteins at $1 \mu \mathrm{g} / \mathrm{ml}$ in TBS-5\% BSA and $1 \mathrm{~mm}$ DTT. After rinsing with TBS $-0.1 \%$ TX and TBS buffers, the membrane was incubated with mouse monoclonal anti-T7 or rabbit polyclonal anti-GST antibodies diluted in TBS-5\% BSA for $2 \mathrm{hr}$. The immune complexes were revealed using HRP goat anti-mouse antibody or HRP protein-A chemiluminescence method. Cell transfection, GST production, and GST binding assays were performed as described previously (Borg et al., 1996). 
A
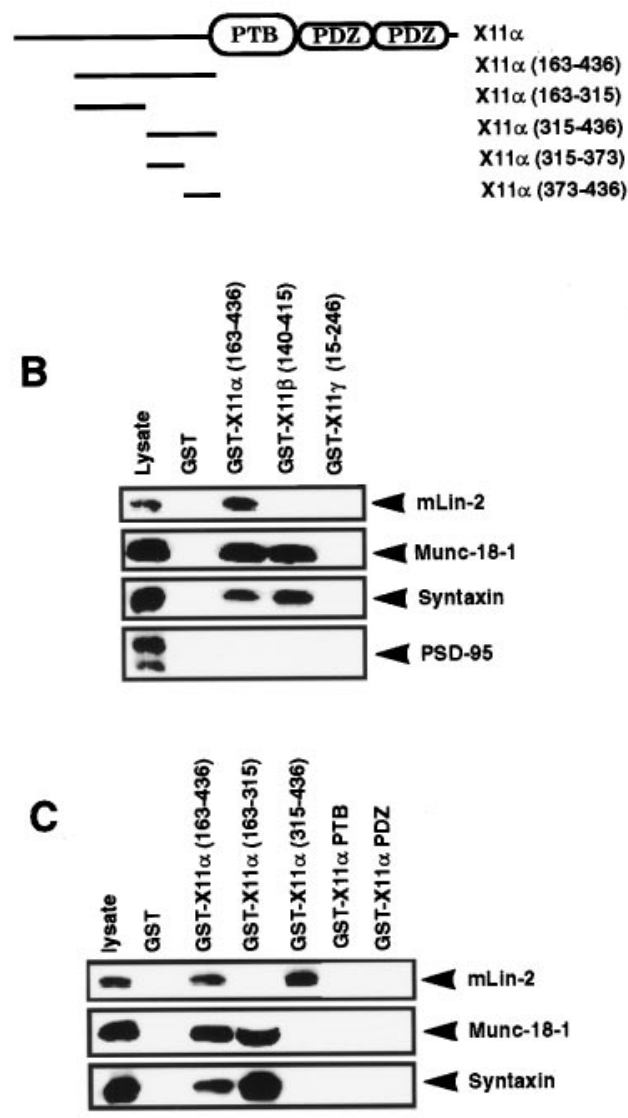

Figure 1. Delineation of the mLin-2/CASK binding site in $\mathrm{X} 11 \alpha$ protein. $A$, Schematic representation of the $\mathrm{X} 11 \alpha$ protein. The $\mathrm{X} 11 \alpha$ protein contains a central PTB domain, followed at its C-terminal end by two PDZ domains. N-terminal fragments were produced as GST fusion proteins. $B$, Proteins extracted from mouse brain were precipitated with GST, GST X11 $\alpha$ (region 163-436), GST X11 $\beta$ (region 140-415), or GST X11 $\gamma$ (region 15-246) coupled to glutathione beads. These fusion proteins incorporate peptides from the $\mathrm{N}$ terminus of these X11 isoforms. After washing, proteins were separated on $10 \%$ SDS-PAGE and transferred to nitrocellulose. The membrane was probed with polyclonal anti-mLin-2/ CASK and monoclonal anti-Munc-18-1, anti-Syntaxin, and anti-PSD-95 antibodies. One-tenth of the lysate used for precipitation was run as control (lysate). Detection was performed by chemiluminescence. $C$, Same as $B$, with additional X11 $\alpha$ fusion proteins. The GST X11 $\alpha$ PTB and PDZ proteins comprise the PTB and the two PDZ domains of the protein, respectively.

\section{RESULTS}

\section{Mapping the $\mathrm{X} 11 \alpha-\mathrm{mLin}-2$ binding sites}

We have further delineated the site of interaction on the $\mathrm{X} 11 \alpha \mathrm{N}$ terminus for mLin-2/CASK (Fig. $1 A$ ). In X11 $\alpha$, the 163-436 amino acids region is responsible for the coimmunoprecipitation between the two proteins (Borg et al., 1998a) and precipitates mLin-2/CASK from mouse brain extracts (Fig. 1B). Analogous regions in $\mathrm{X} 11 \beta$ and $\mathrm{X} 11 \gamma$ do not interact with mLin-2/CASK. As shown previously, $\mathrm{X} 11 \alpha$ and $\mathrm{X} 11 \beta \mathrm{N}$ termini bind to the complex of Munc-18-1 and Syntaxin (Okamoto and Sudhof, 1997). In contrast, we found no interaction between Munc-18-1 or Syntaxin and the $\mathrm{X} 11 \gamma \mathrm{N}$ terminus. PSD-95 did not bind to X11 fusion proteins (Fig. 1B). We have generated GST fusion proteins representing smaller peptides of $\mathrm{X} 11 \alpha$ and examined the binding to mLin-2/CASK by GST precipitation (Fig. $1 C$; Table 1). We demonstrate that a region encompassing residues 373-436 in

\begin{tabular}{lll}
\hline \multicolumn{2}{l}{ Table 1. X11 $\alpha$ (region 373-436) } & is the minimal binding site for mLin-2 \\
X11 $\alpha$ peptides & mLin-2 & Munc-18-1 \\
\hline $163-436$ & +++ & +++ \\
$163-315$ & - & +++ \\
$315-436$ & +++ & - \\
$315-373$ & - & - \\
$373-436$ & ++ & - \\
$373-392$ & - & NT \\
$373-402$ & - & NT \\
$390-408$ & - & NT \\
$390-425$ & - & NT
\end{tabular}

X11 $\alpha$ peptides fused to the GST protein were used to pull down mLin-2 from a 293 cells lysate or mouse brain extract. Bound protein was detected by Western blot or overlay assays. Binding to X11 $\alpha$ (region 373-436) was reproducibly weaker than to larger peptides. NT, Non-tested.

$\mathrm{X} 11 \alpha$ is sufficient to bind mLin-2/CASK. No binding was detected with the $\mathrm{X} 11 \alpha \mathrm{PTB}$ and PDZ domains (Fig. $1 C$ ). The binding site was further subdivided in shorter peptides, but none of them could bind to mLin-2/CASK, suggesting that the X11 $\alpha$ region 373-436 represents the minimal site of interaction (Table $1)$. As expected, no homologous regions are found in $\mathrm{X} 11 \beta$ and $\mathrm{X} 11 \gamma$. Others have found that the region $226-314$ in $\mathrm{X} 11 \alpha$ is sufficient to bind Munc-18-1 (Okamoto and Sudhof, 1997). Accordingly, GST X11 $\alpha$ (region 163-315) binds efficiently to the Munc-18-1-Syntaxin complex (Fig. 1C). Together, these data show that mLin-2/CASK and Munc-18-1 proteins bind to the $\mathrm{X} 11 \alpha \mathrm{N}$ terminus on two different sites.

The first 320 amino acids of mLin-2/CASK encompassing the CKII domain directly binds to full-length X11 $\alpha$ by overlay assay (Borg et al., 1998a). We used this assay to show that this region interacts with the $\mathrm{X} 11 \alpha$ (region 373-436) peptide (Fig. 2A). Binding of GST mLin-2/CASK (region 1-320) to X11 $\alpha$ was inhibited at a concentration of $250 \mathrm{~nm}$ soluble His-mLin-2/CASK (region 1-320), whereas $5 \mu \mathrm{M}$ control protein did not affect the binding (Fig. 2B). These data allow us to conclude that mLin-2/ CASK (region 1-320) binds tightly to the 63 amino acid peptide found in the $\mathrm{X} 11 \alpha \mathrm{N}$ terminus.

The mLin-2/CASK region 1-320 contains a CKII domain, followed by a calmodulin binding site (residues 294-320). We asked whether the peptide (region 294-320) was involved in the binding with $\mathrm{X} 11 \alpha$. Various mLin-2/CASK GST fusion proteins were used to precipitate myc-tagged X11 $\alpha$ expressed in 293 cells (Fig. 3A). Bound proteins were resolved by SDS-PAGE, transferred to nitrocellulose, and revealed with anti-myc antibody. GST mLin-2/CASK (region 1-294) does not contain the calmodulin binding site but still binds very well to $\mathrm{X} 11 \alpha$ (Fig. $3 B$ ). We also introduced deletions within the CKII domain of mLin-2/ CASK; truncated CKII protein does not bind to X11 $\alpha$, suggesting that residues 1-294 are required for the proper folding and/or function of the domain (Fig. 3C).

\section{Calmodulin binds to mLin-2/CASK and does not affect $\mathrm{X} 11 \alpha-\mathrm{mLin}-2 / \mathrm{CASK}$ interaction}

Our next experiments aimed to determine the role of calmodulin in $\mathrm{X} 11 \alpha-\mathrm{mLin}-2 / \mathrm{CASK}$ association. Calmodulin-dependent kinases require the binding of $\mathrm{Ca}^{2+} /$ calmodulin to activate their catalytic activity (Goldberg et al., 1996). It has been suggested that $\mathrm{Ca}^{2+} /$ calmodulin binds to a GST mLin-2/CASK fusion protein (Hata et al., 1996). We used an in vitro binding assay to detect an interaction between the mLin-2/CASK (region 294-320) pep- 


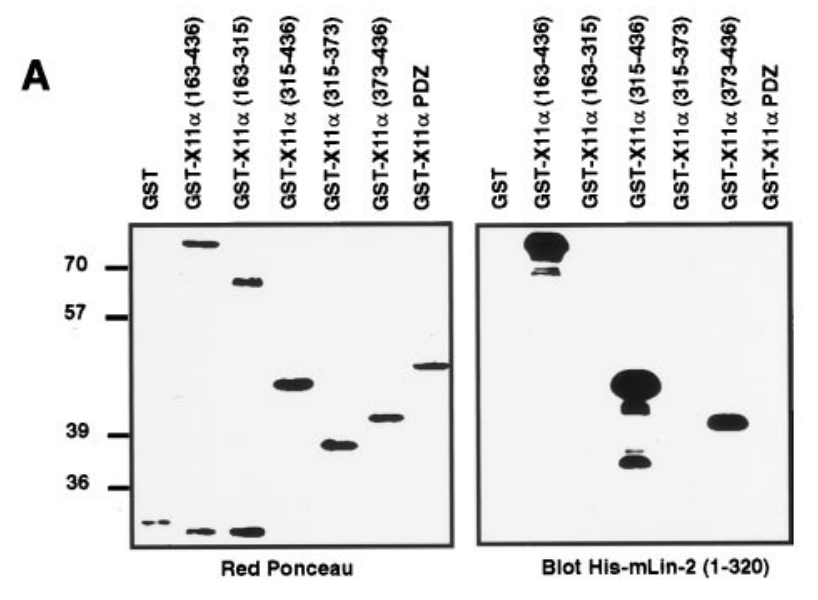

B

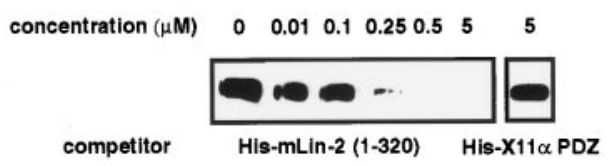

Figure 2. The mLin-2/CASK CKII domain directly binds to an X11 $\alpha$ (region 373-436) peptide. $A$, GST fusion proteins described in Figure $1 C$ were subjected to SDS-PAGE and transferred to nitrocellulose. Equivalent amounts of proteins were revealed with Ponceau red stain (left). The membrane was probed with soluble His-mLin-2/CASK (region 1-320) protein, and bound proteins were revealed with anti-T7 antibody, followed by HRP goat anti-mouse and chemiluminescence detection (right). $B$, The same procedure was performed to detect $\mathrm{X} 11 \alpha$ in 293 cell lysate, except that soluble GST mLin-2/CASK (region 1-320) protein was used as primary reagent and anti-GST antibody-HRP protein A as secondary reagents. Increasing concentrations of soluble His-mLin-2/CASK (region 1-320) were mixed with a fixed concentration of soluble GST mLin-2/ CASK (region 1-320) protein to compete for binding to X11 $\alpha$. A soluble His-X11 $\alpha$ PDZ containing the two X11 $\alpha$ PDZ domains was used as a negative control.

tide and purified calmodulin. Increasing amounts of calmodulin were incubated with immobilized GST mLin-2/CASK (regions 1-320 or 1-294) fusion proteins. Binding assays were performed in the presence of $0.1 \mathrm{~mm} \mathrm{CaCl}_{2}$ or $1 \mathrm{~mm}$ EGTA. After incubation, beads were washed, and bound calmodulin was revealed by Western blot with anti-calmodulin antibody. Figure $4 A$ shows that calmodulin binds to the peptide (region 294-320) in a $\mathrm{Ca}^{2+}$ dependent manner. No binding was evident when EGTA was added. Furthermore, we could coimmunoprecipitate calmodulin and mLin-2/CASK from A-172 cell lysate (Fig. 4B). Binding of $\mathrm{Ca}^{2+} /$ calmodulin to GST mLin-2/CASK (region 1-320) does not affect the binding of X11 $\alpha$ to the CKII domain (Fig. $4 C$ ), suggesting that the $\mathrm{X} 11 \alpha-\mathrm{mLin}-2 / \mathrm{CASK}$ interaction is not regulated by calmodulin.

\section{A region of $\mathrm{mLin}-2 / \mathrm{CASK}$ encompassing the GK domain binds to $\mathrm{X} 11 \alpha$}

We found that the mLin-2/CASK CKII domain is crucial for in vivo interaction with $\mathrm{X} 11 \alpha$. Indeed, a mLin-2/CASK protein containing only the CKII and PDZ domains (region 1-612) coimmunoprecipitates with $\mathrm{X} 11 \alpha$, and this binding is conferred by the CKII domain (Borg et al., 1998a). However, in vitro
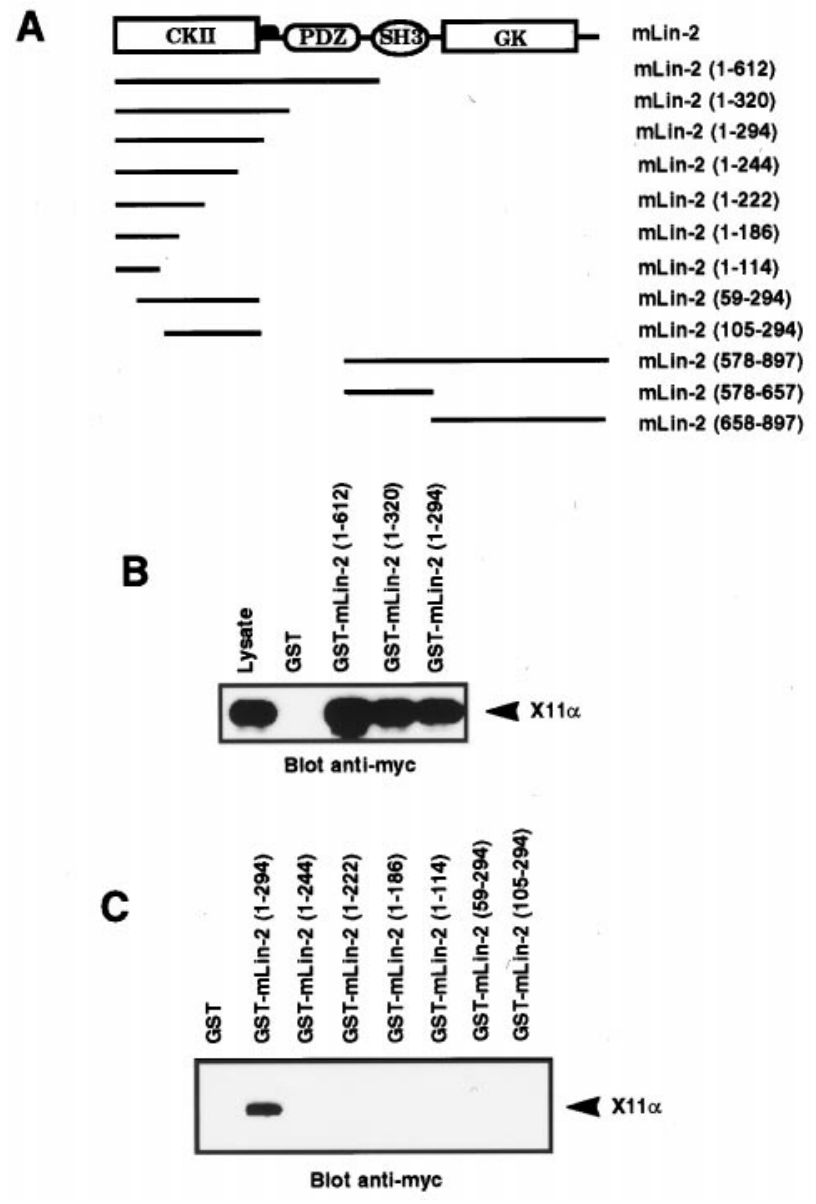

Figure 3. An integral mLin-2/CASK CKII domain is required for binding to X11 $\alpha$. $A$, Schematic representation of mLin-2/CASK and GST fusion proteins used in this study. B, Myc-tagged X11 $\alpha$ expressed in 293 cells was precipitated by mLin-2/CASK GST coupled to glutathione beads, and bound proteins were revealed by Western blot with anti-myc antibody. $C$, Same as $B$, with different mLin-2/CASK constructs.

binding assays led us to consider also an interaction between $\mathrm{X} 11 \alpha$ and the second half of mLin-2/CASK containing an SH3 and GK domain (region 578-897). In Figure 5A, we show that the GST mLin-2/CASK (regions 1-612 and 578-897) fusion proteins bind to $\mathrm{X} 11 \alpha$ in a specific manner because neither X11 $\beta$ nor X $11 \gamma$ can bind to these fusion proteins (Fig. 5A; data not shown). Binding of $\mathrm{X} 11 \alpha$ to mLin-2/CASK (region 578-897) was reproducibly weaker than binding to mLin-2/CASK (region 1-612). This interaction is direct because soluble GST mLin-2/CASK (region 578-897) binds to $\mathrm{X} 11 \alpha$ in an overlay assay (Fig. 5B). Whereas GST mLin-2/CASK (region 1-320) detects X11 $\alpha$ in brain lysate, no signal is obtained with GST mLin-2/CASK (region 578-897), suggesting again a low-affinity interaction. The $\mathrm{SH} 3$ domain of mLin-2/CASK does not participate in this interaction because GST mLin-2/CASK (region 658-897) is sufficient for binding to $\mathrm{X} 11 \alpha$ (Fig. $5 C$ ). We were also able to exclude a role for the lysine-rich band 4.1 binding regions (Cohen et al., 1998) because an mLin-2/CASK GST construct containing amino acids $700-897$ was also able to bind $\mathrm{X} 11 \alpha$ (results not shown). Thus, both the CKII and the GK domain containing regions in mLin2/CASK bind to X11 $\alpha$. This dual contact probably increases the interaction between the two partners. 
A
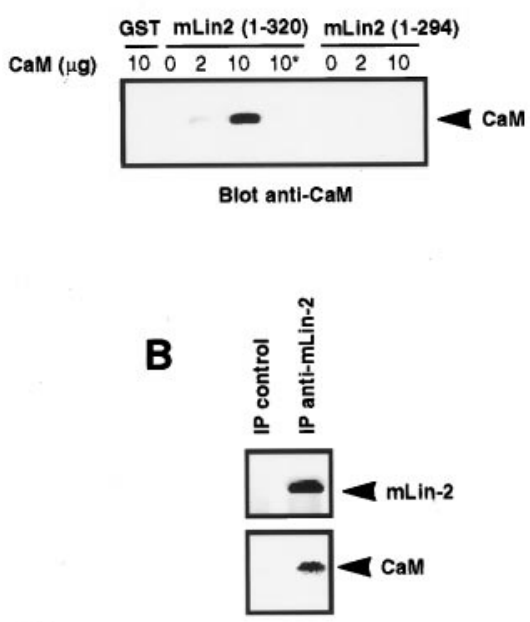

C

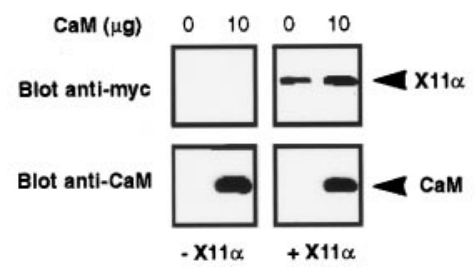

Figure 4. Calmodulin binds to mLin-2/CASK but does not affect $\mathrm{X} 11 \alpha-$ mLin-2 interaction. $A$, GST and GST mLin-2/CASK (regions 1-320 and 1-294) were incubated with 0,2 , or $10 \mu \mathrm{g}$ of calmodulin in the presence of $0.1 \mathrm{~mm} \mathrm{Ca}^{2+}$ or $1 \mathrm{~mm}$ EGTA (asterisk). After washing, bound calmodulin was resolved on SDS-PAGE, transferred to nitrocellulose, and detected with anti-calmodulin antibody. B, Lysates from untransfected A-172 cells were immunoprecipitated with preimmune or immune antimLin-2/CASK antibodies, and bound proteins were resolved on SDSPAGE and transferred to nitrocellulose. Proteins were successively revealed with anti-mLin-2/CASK (top) and anti-calmodulin (bottom) antibodies. $C$, GST mLin-2/CASK (region 1-320) fusion protein immobilized on glutathione beads was incubated with $\mathrm{Ca}^{2+} /$ calmodulin, and then lysate with $(+X 11 \alpha)$ or without $(-X 11 \alpha)$ myc-tagged $\mathrm{X} 11 \alpha$ was added. Bound calmodulin and $\mathrm{X} 11 \alpha$ was then assessed using immunoblotting.

\section{Localization of $\mathrm{X} 11 \alpha$ in the brain}

To examine the expression pattern of $\mathrm{X} 11 \alpha$, protein extracts from various organs were run on SDS-PAGE, transferred to nitrocellulose, and revealed with anti-X11 antibody. X11 $\alpha$ is only expressed in the brain, whereas mLin-2/CASK is present in all tissues (Fig. 6A). Previous analyses have shown that $X 11 \alpha$ is detected in the cerebellum and hippocampus in mouse brain by in situ hybridization analysis (Duclos et al., 1993). We obtained similar results with a human $X 11 \alpha$ probe in rat brains (Fig. 6E). In addition, strong labeling was observed in the olfactory system, the piriform and enthorinal cortex, the supraoptic nucleus of the hypothalamus, the substantia nigra, and other mesencephalic areas. In control experiments using a sense RNA probe, no signal was observed (data not shown). We performed immunostaining with anti-X11 $\alpha$ antibody on rat brain sections to document the localization of the protein. No signal was detected when antibody was preincubated with the immunogen (Fig. 6, compare $B, D$ ). The substantia nigra is strongly stained by anti-X11 $\alpha$ antibody, and this expression correlates with a positive signal by in situ hybridization (Fig. 6E). High magnification of neurons in sub-

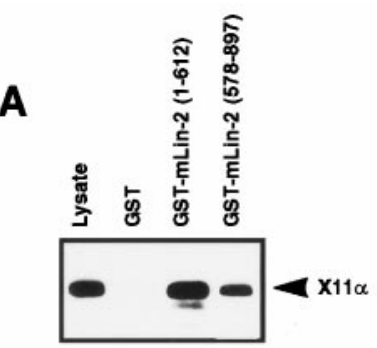

B
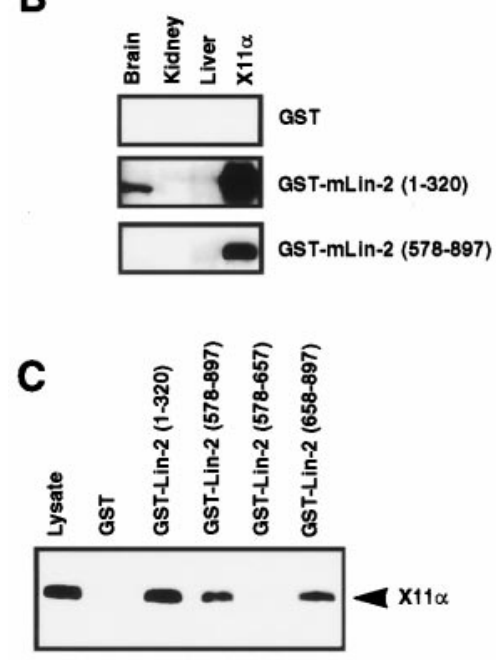

Figure 5. A region of mLin-2/CASK encompassing the GK domain binds to $\mathrm{X} 11 \alpha$. $A, C$, Myc-tagged $\mathrm{X} 11 \alpha$ protein expressed in 293 cells was precipitated with different mLin-2/CASK GST fusion proteins and revealed with anti-myc antibody after Western blot. We have also detected binding to nonmyc-tagged constructs (results not shown). $B$, Brain, liver, and kidney extracts were run on a gel, and proteins were transferred to nitrocellulose. Myc-tagged X11 $\alpha$ protein expressed in 293 cells was used as a positive control $(X 11 \alpha)$. An overlay assay was performed with soluble GST fusion proteins. Bound GST proteins were revealed using anti-GST antibody-HRP protein A chemiluminescence method.

stantia nigra shows a diffuse staining in intracellular compartments, with exclusion of nuclei (Fig. 6C).

Several rat brain sections were stained to study X11 $\alpha$ expression in more detail. X11 $\alpha$-positive immunostaining was observed in several nuclei throughout the rat brain. Within the telencefalon, the main olfactory bulb exhibited heavy staining, especially in the mitral and external plexiform layers. In addition, some staining was observed in the glomerular layer (Fig. 7A,B). The internal granule cell layer was basically unstained. The piriform cortex exhibited a large number of intensely stained neurons, which were continuous through the entorhinal cortex (Fig. $7 C, D$ ). Throughout the cortex, layer $\mathrm{V}$ was stained with $\mathrm{X} 11 \alpha$ neurons (Fig. $7 G$ ). In addition, layers II-IV also exhibited weak staining, whereas layer I was devoid of staining (data not shown). Within the striatum, X11 $\alpha$-immunopositive medium-sized neurons were scattered in distribution (Fig. $7 E$ ). The striatal neurons exhibited a characteristic punctuate labeling (Fig. $7 F$ ). Furthermore, scattered stained neurons were observed in the septum, nucleus accumbens, substantia innominata, and olfactory tubercle. In the nucleus of the diagonal band and the medial preoptic nucleus, numerous positive cells of various sizes and intensity of staining were observed. Few intensely stained and scattered neurons were observed in the hippocampus. In addition, the dentate gyrus 
A
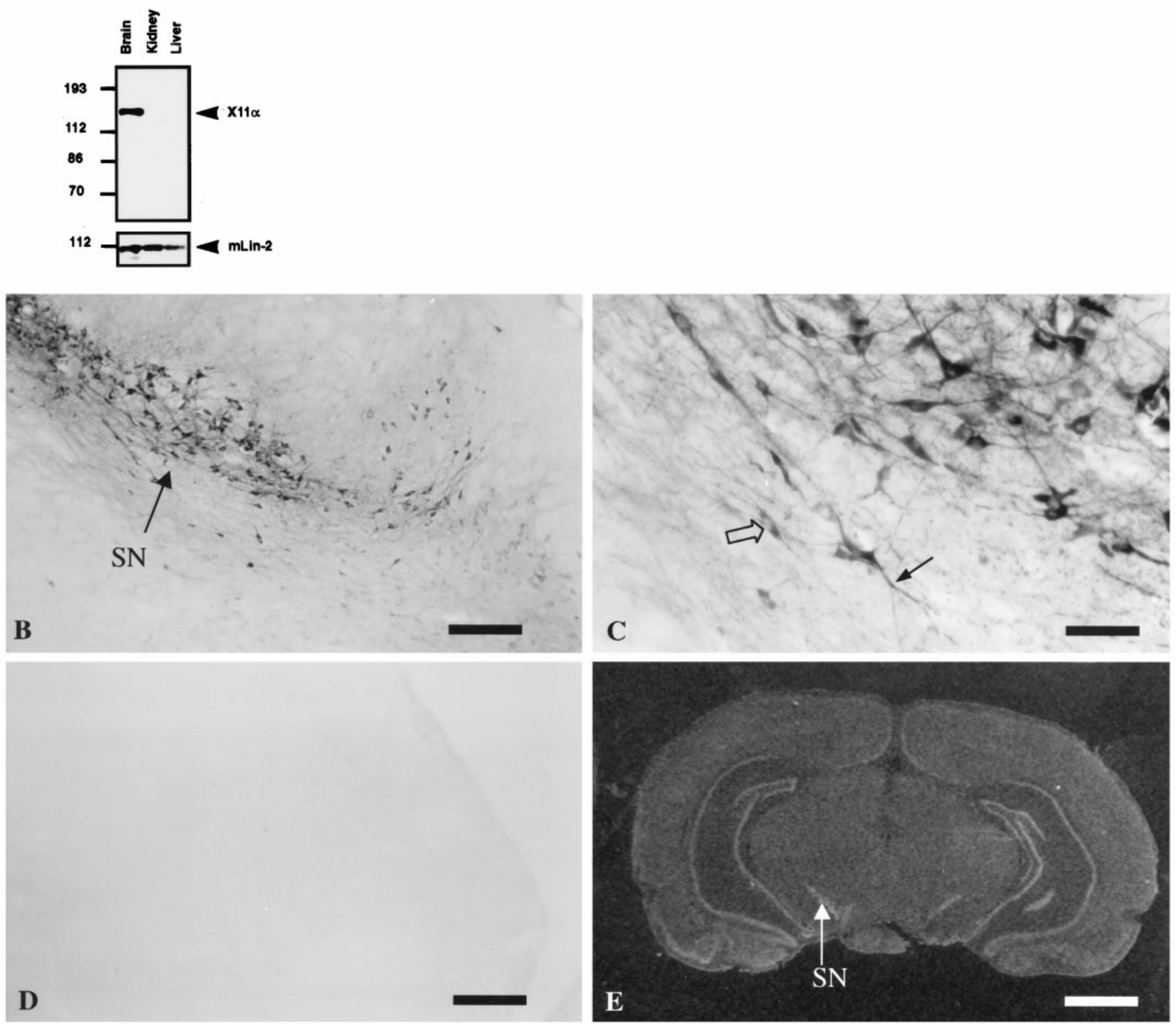

Figure 6. $\mathrm{X} 11 \alpha$ is a brain-specific protein. $A$, Total proteins extracted from mouse brain, kidney, and liver were resolved by $8 \%$ SDS-PAGE and transferred to nitrocellulose. Immunoblot with anti-X11 $\alpha$ antibody detects X11 $\alpha$ only in the brain. mLin-2/CASK is present in all tissues, as observed previously (Hata et al., 1996; Cohen et al., 1998). $B$, X11 $\alpha$-positive immunostaining in substantia nigra $(S N)$. Scale bar, $300 \mu$ m. $C$, High magnification of the substantia nigra showing neuronal somata, with exclusion of the nucleus (open arrow) and positive dendrites ( filled arrow). Scale bar, $50 \mu \mathrm{m}$. $D$ Same as $B$, but the anti-X11 $\alpha$ antibody was preincubated with X11 $\alpha$ peptide. E, In situ hybridization of rat brain with the X11 $\alpha$ probe. The arrow shows the substantia nigra labeling. Scale bar, $0.2 \mathrm{~cm}$.

exhibited a denser staining. Several amygdaloid nuclei contained large and intensely $\mathrm{X} 11 \alpha$-stained neurons. Caudally in the diencephalon, many hypothalamic and thalamic nuclei exhibited positive-stained neurons of various sizes and intensity. For instance, a dense group of heavily stained neurons was present in the supraoptic nucleus and dorsally in the habenula. Intense staining was also present in the median eminence.

Within the mesencephalon, scattered positive neurons were observed in the superior and inferior colliculus. A large number of heavily stained neurons, together with a dense fiber network, was present in the substantia nigra, gigantocellular reticular nucleus, and red nucleus (Fig. $7 H$ ). There was also a moderate staining in neurons of the dorsal raphe, as well as in the dorsal cochlear nucleus. Many nuclei within the caudal-most region of the brain corresponding to pons and medulla exhibited a large number of intensely stained neurons and fibers. Cells within these region exhibited a characteristic punctuate staining of the soma, axons, and dendrites, whereas in most cases, the nucleus was devoid of staining. The cerebellum exhibited a moderate staining, with intense staining of the Purkinje cells (data not shown).

\section{Localization of X11 $\alpha-\mathrm{mLin}-2$ in NT2 neurons}

In our next series of studies, we wanted to determine where these proteins might interact within cells. To examine the localization 

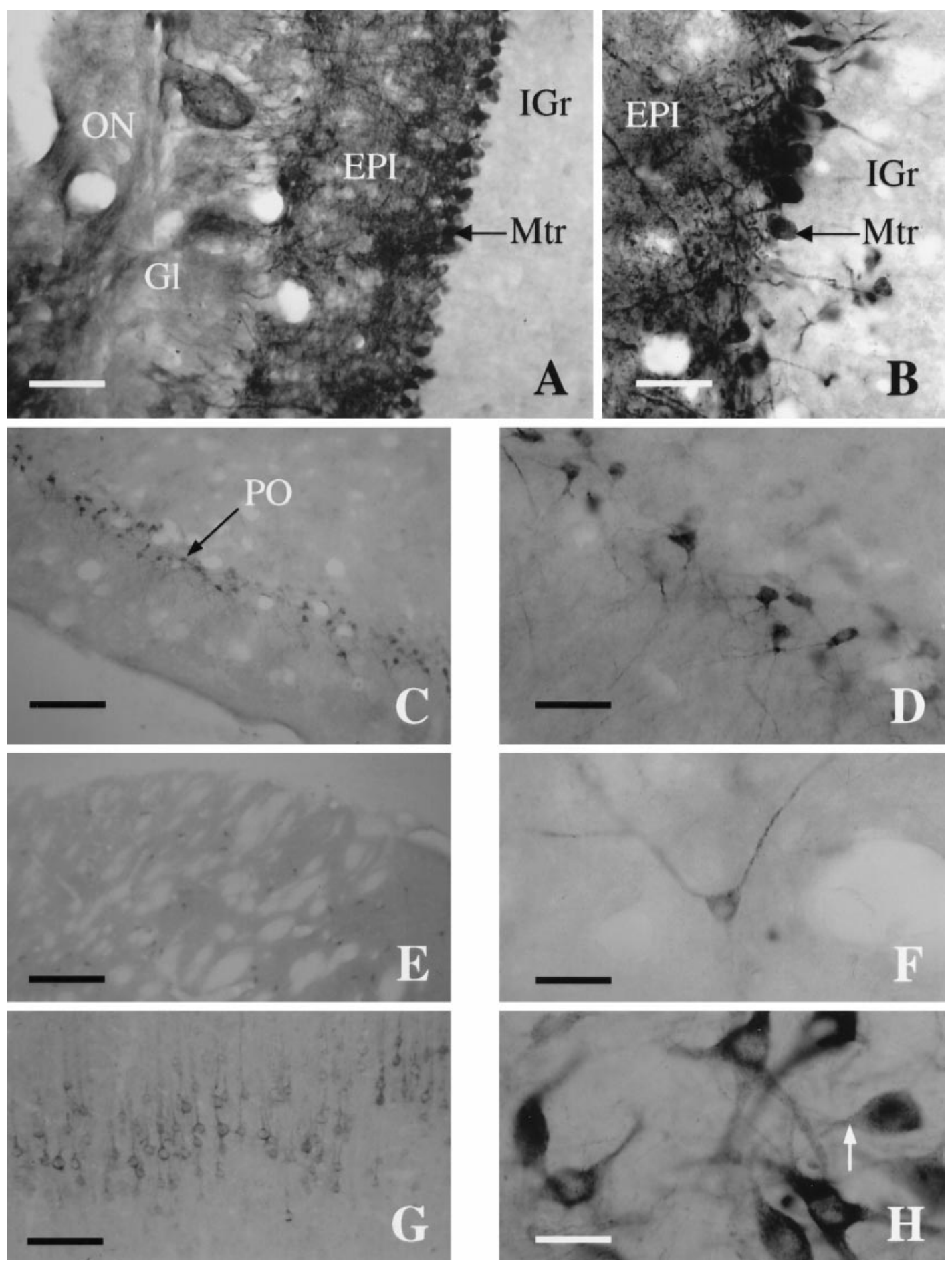

Figure 7. X11 $\alpha$ immunostaining in the rat brain. $A$, Photomicrograph of a coronal section through the main olfactory bulb (MOB) immunostained for $\mathrm{X} 11 \alpha$. Scale bar, $15 \mu \mathrm{m}$. $B$, High-magnification photomicrograph of the main olfactory bulb showing dense staining of the mitral cell layer. Note the intensely labeled dendrites extending to the glomerular layer. Scale bar, $40 \mu \mathrm{m}$. $C$, Coronal section through the piriform cortex $(P O)$. Scale bar, $230 \mu \mathrm{m}$. $D$, High-magnification photomicrograph of the intensely stained pyramidal cells of layer 2 of the piriform. Scale bar, $40 \mu \mathrm{m}$. $E$, X11 $\alpha$-immunostained section exhibiting scattered cells in the striatum. Scale bar, $230 \mu \mathrm{m}$. F, Detail of a X11 $\alpha$-positive neuron in the striatum. Note the punctuate labeling along the axon. Scale bar, $40 \mu \mathrm{m}$. $G$, Coronal section through the cortex stained with X11 $\alpha$ antibody. The staining is most prominent in layer V. Scale bar, 100 $\mu \mathrm{m}$. $H$, High-magnification photomicrograph at the level of the substantia nigra with cells strongly stained for X11 $\alpha$. Note the lack of nuclear staining and the punctuate labeling. Scale bar, $40 \mu \mathrm{m}$.

of these proteins within neurons, we performed immunostaining of human NT2 neurons. NT2 teratocarcinoma cells form neurons when differentiated with retinoic acid (Pleasure and Lee, 1993). $\mathrm{X} 11 \alpha$ is expressed in the differentiated NT2 cells but not in the stem cells (Fig. 8A). Staining of cells with anti-X11 $\alpha$ antibodies indicates that the endogenous protein is localized in the cytosol and in a perinuclear region (Figs. $8 A, B$ ). A similar localization was seen when a myc-tagged $\mathrm{X} 11 \alpha$ protein was expressed in $\mathrm{PC} 12$ 


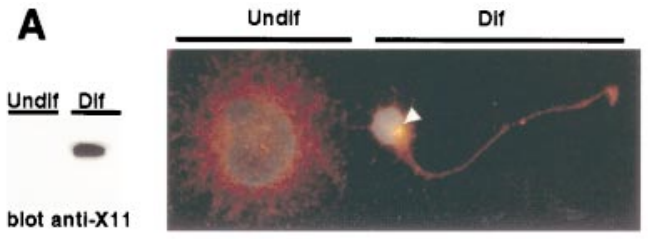

B
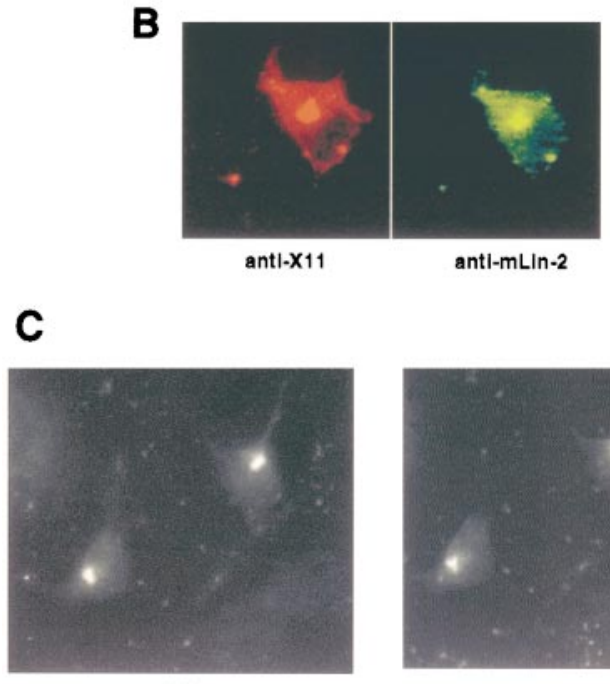

antI-X11

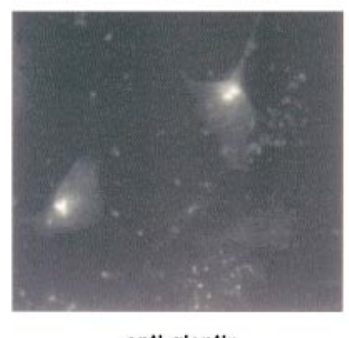

antl-giantın

Figure 8. Colocalization of $\mathrm{X} 11 \alpha$ and mLin-2/CASK in differentiated NT2 cells. $A$, Undifferentiated (Undif) or differentiated (Dif) NT2 cells treated with retinoic acid were lysed, and equal amounts of proteins were subjected to Western blot. The membrane was revealed with anti-X11 antibody (left). Cells were also stained with anti-X11 antibody and the nuclear stain 4-6-diamidino-2-phenylindole. White arrow indicates the restricted localization of $\mathrm{X} 11 \alpha$ in a differentiated (Dif) neuron. The cell at the left represents an undifferentiated (Undif) NT2 cell. B, Immunostaining of a differentiated NT2 cell with anti-X11 (left, Cy3-coupled secondary antibody) and anti-mLin-2/CASK (right, FITC-coupled secondary antibody). $C$, Immunostaining of a differentiated neuron with anti-X11 (left, FITC-coupled secondary antibody) and anti-giantin (right, Cy3-coupled secondary antibody) antibodies.

cells (data not shown). Lin-10 has also been localized to the perinuclear region in C. elegans neurons (Rongo et al., 1998). mLin-2/CASK localized to the same regions in cells (Fig. 8B). The perinuclear region represents a component of the wheat germ ag-stained regions (results not shown). Furthermore, X11 $\alpha$ colocalizes with giantin, suggesting that X11 $\alpha$ and mLin-2/CASK are in a fraction of the golgi apparatus (Linstedt and Hausi, 1993). Interestingly, APP, an X11 $\alpha$ partner, is also predominately located in the golgi and trans-golgi network in neurons (Caporaso et al., 1994).

\section{DISCUSSION}

This study further delineates the interaction between $\mathrm{X} 11 \alpha$ and mLin-2/CASK, two proteins involved in receptor localization in neurons (Borg et al., 1998a; Butz et al., 1998; Kaech et al., 1998; Rongo et al., 1998). We show that a 63 amino acid peptide found in X11 $\alpha$ interacts with the mLin-2/CASK CKII domain. Munc$18-1$, another $\mathrm{X} 11 \alpha$ partner, binds to a different location in the $\mathrm{X} 11 \alpha \mathrm{N}$ terminus. Genetic analyses have suggested that the Lin-2 CKII domain acts like a protein-protein interaction domain rather than a kinase (Hoskins et al., 1996). A similar conclusion is drawn from our biochemical data with the mLin-2/CASK CKII domain. Calmodulin is a cellular calcium sensor for many enzymes and regulates ion channels, cell cycle, and cytoskeletal organization (James et al., 1995). Furthermore, previous studies have demonstrated a role for calmodulin as a negative regulator of protein-protein interactions (Wyszynski et al., 1997). In contrast, we show that calmodulin binding does not affect $\mathrm{X} 11 \alpha-$ mLin-2 interaction. Deletion analysis of the mLin-2/CASK CKII domain has demonstrated that the integrity of the CKII domain is required for proper binding to $\mathrm{X} 11 \alpha$. We also describe an interaction between the mLin-2/CASK $\mathrm{C}$ terminus containing a GK domain and $\mathrm{X} 11 \alpha$. This interaction is weaker than the interaction between the CKII domain of mLin-2/CASK and X11 $\alpha$. Accordingly, we feel that this interaction involving the GK domain may increase the avidity of X11 with mLin-2/CASK but cannot be solely responsible for the interaction. In C. elegans, a lin-2 transgene, mutated to produce a protein with a catalytically inactive GK domain, is able to rescue the vulvaless phenotype caused by lin-2 mutations (Hoskins et al., 1996). Furthermore, the GK domain of PSD-95 and synaptic scaffolding molecule interacts with proteins found in postsynaptic densities (Kim et al., 1997; Hirao et al., 1998). Together, these data argue that the GK domain of MAGUK proteins acts as a protein-protein interaction domain.

APP, neurexins, and syndecans bind to the PTB and PDZ domains found in the X11 $\alpha$-mLin-2 complex (Borg et al., 1996, 1998a; Hata et al., 1996; Cohen et al., 1998; Hsueh et al., 1998). Additionally, it has been shown that mLin-7 binds tightly to mLin-2/CASK (Borg et al., 1998a; Butz et al., 1998; Kaech et al., 1998). Considering that the PDZ domains of mLin-7 and $\mathrm{X} 11 \alpha$ and the SH3 domain of mLin-2/CASK are also available for interactions, further studies will certainly increase the number of interactors found in this complex. Such complexity is common for PDZ domain proteins. For example, in Drosophila, inactivation no afterpotential D (INAD), a PDZ protein, contacts multiple partners (phospholipase C, calmodulin, rhodopsin, and TRP ion channel) important in phototransduction (Xu et al., 1998). In worms, the Lin-10-Lin-2-Lin-7 heterotrimeric complex targets Let-23 to the basolateral epithelium in vulva (Kaech et al., 1998). In mammals, no precise role has been assigned to the complex, but a role in receptor localization is probable. Munc-18-1-Syntaxin is a brain-specific plasma membrane complex involved in the docking of vesicles during exocytosis (Hata et al., 1993). A possible scenario is that the $\mathrm{X} 11 \alpha-\mathrm{mLin}-2-\mathrm{mLin}-7$ complex binds to Munc-18-1-Syntaxin at the plasma membrane to deliver receptors such as APP, neurexins, and syndecans. We have tried to detect an in vivo interaction between the heterotrimeric complex and Munc-18-1-yntaxin. Although we could easily coimmunoprecipitate $\mathrm{X} 11 \alpha$, mLin-2/CASK, and mLin-7 from mouse brain extracts, our attempts to demonstrate a coimmunoprecipitation with Munc-18-1-Syntaxin were unsuccessful. However, other groups have detected a complex containing X11 $\alpha /$ Mint- 1 and Munc-18-1 (Okamoto and Sudhof, 1997).

In situ hybridization data show that $\mathrm{X} 11 \alpha$ is present in the hippocampus, cerebral cortex, anterior thalamic nuclei, and cerebellum. In addition, positive signal was observed in the olfactory bulb, the piriform cortex, hypothalamus, and other thalamic areas, as well as numerous brainstem areas. Immunohistochemical data demonstrate that, in general, protein and mRNA follow a similar pattern for $\mathrm{X} 11 \alpha$ distribution. However, in some areas, such as the hippocampus, mRNA expression was highly abundant, but protein levels appeared to be relatively low. These differences may be explained by a high level of mRNA expression versus a 


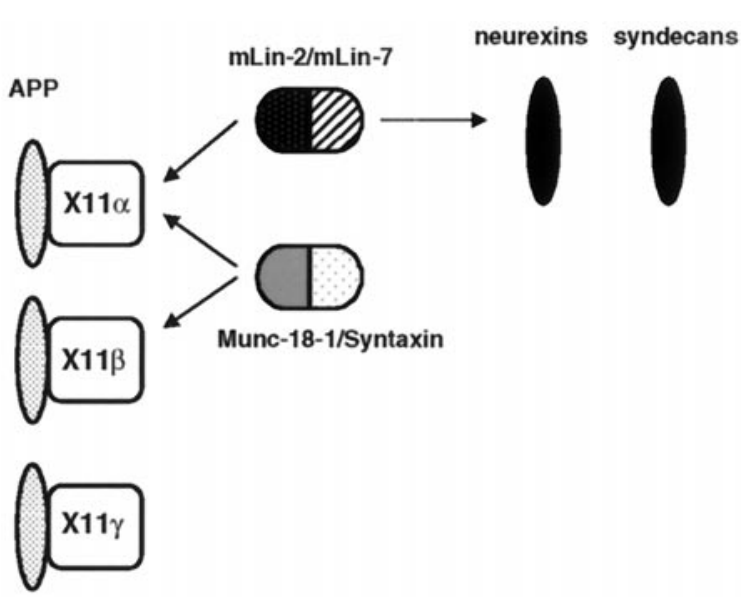

Figure 9. The X11 protein family participates in multiple protein complexes in neurons. Schematic representation of the different proteins interacting with $\mathrm{X} 11$ proteins. $\mathrm{X} 11 \alpha$ and $\mathrm{X} 11 \beta$ are highly expressed in brain, whereas X11 $\gamma$ is ubiquitously expressed. APP binds to all three X11 PTB domains, whereas the mLin-2/CASK-mLin-7 complex only interacts with X11 $\alpha$. The Munc-18-1-Syntaxin neuronal complex interacts with the neuronal X11 species. Neurexins and syndecans binds to the mLin-2/ CASK PDZ domain.

low translational rate and/or a high proteolytic rate. mLin-2/ CASK is ubiquitously expressed, with a predominant expression in the brain (Hata et al., 1996; Cohen et al., 1998) (Fig. 6A). Like $\mathrm{X} 11 \alpha, \mathrm{mLin}-2 / \mathrm{CASK}$ is distributed in a punctate somatodendritic pattern in neurons. Many regions are positive for $\mathrm{X} 11 \alpha$ and mLin-2/CASK expression. For example, cortical layer V pyramidal neurons and their apical dendrites present an overlapping staining. The same punctate nature of staining is seen in pyramidal cell dendrites, which suggests a synaptic localization of the two proteins. X11 $\alpha$ and mLin-2/CASK are also found in neurons of the thalamus and in Purkinje cells of the cerebellum (Hsueh et al., 1998). However, mLin-2/CASK has not been described in some other areas, such as the hypothalamus or brainstem nuclei, where $\mathrm{X} 11 \alpha$ is expressed. A more complete study of the distribution of mLin-2/CASK may reveal a wider distribution than previously described. Unfortunately, the anti-mLin-2/CASK that we produced and the commercially available anti-mLin-2/CASK antibodies did not give any specific signal in rat brain immunohistochemistry. We find this complex in neurons, where it is likely to play an important role in the localization of proteins to presynaptic or postsynaptic sites. In human neurons, $\mathrm{X} 11 \alpha$ is found in the cytosol and in a component of the golgi network. Although the significance of this localization is presently unclear, we speculate that $\mathrm{X} 11 \alpha$ in these compartments is required for the proper targeting of receptors. Although we could not localize mLin-2/ CASK to specific structures other than the golgi in NT2 neurons, recent studies have also localized the protein to synapses and basolateral membranes of epithelial cells (Cohen et al., 1998; Hsueh et al., 1998).

The $X 11 \beta$ gene is also expressed in the brain, and the encoded protein is functionally related to X11 $\alpha$ because it binds to APP and Munc-18-1-Syntaxin (Okamoto and Sudhof, 1997; Borg et al., 1998b). The lack of binding to mLin-2/CASK probably creates functional differences with X11 $\alpha$. Finally, X11 $\gamma$ does not bind to mLin-2/CASK and Munc-18-1 but still binds to APP. In neurons, APP is associated with at least three different intracellular complexes containing X11 proteins (Fig. 9). An alteration in localization of APP or its retention in a subcellular compartment induced by $\mathrm{X} 11 \alpha$ may explain the effects of $\mathrm{X} 11 \alpha$ on the processing of APP (Borg et al., 1998b). Additionally, members of the Fe65 protein family bind to the cytoplasmic region of APP (Borg et al., 1996; Fiore et al., 1996; Guenette et al., 1996; Trommsdorff et al., 1998). These multiple complexes may play a role in normal and pathological metabolism of APP in neurons.

\section{REFERENCES}

Borg J-P, Margolis B (1998) Function of PTB domains. Curr Top Microbiol Immunol 228:23-38.

Borg J-P, Ooi J, Levy E, Margolis B (1996) The phosphotyrosine interaction domains of X11 and FE65 bind to distinct sites on the YENPTY motif of amyloid precursor protein. Mol Cell Biol 16:6229-6241.

Borg J-P, Straight SW, Kaech SM, De Taddeo-Borg M, Kroon DE, Karnak D, Turner RS, Kim SK, Margolis B (1998a) Identification of an evolutionarily conserved heterotrimeric protein complex involved in protein targeting. J Biol Chem 273:31633-31636.

Borg J-P, Yang Y, De Taddeo-Borg M, Margolis B, Turner RS (1998b) The X11 $\alpha$ protein slows cellular amyloid precursor protein processing and reduces $A \beta 40$ and $A \beta 42$ secretion. J Biol Chem 273:14761-14766.

Butz S, Okamoto M, Sudhof TC (1998) A tripartite protein complex with the potential to couple synaptic vesicle exocytosis to cell adhesion in brain. Cell 94:773-782.

Caporaso GL, Takei K, Gandy SE, Matteoli M, Mundigl O, Greengard P, De Camilli P (1994) Morphologic and biochemical analysis of the intracellular trafficking of the Alzheimer beta/A4 amyloid precursor protein. J Neurosci 14:3122-3138.

Cohen AR, Wood DF, Marfatia SM, Walther Z, Chishti AH, Anderson JM (1998) Human CASK/LIN-2 binds syndecan-2 and protein 4.1 and localizes to the basolateral membrane of epithelial cells. J Cell Biol 142:129-138.

Duclos F, Boschert U, Sirugo G, Mandel J-L, Hen R, Koenig M (1993) Gene in the region of the Friedreich ataxia locus encodes a putative transmembrane protein expressed in the nervous system. Proc Natl Acad Sci USA 90:109-113.

Fanning AS, Anderson JM (1997) PDZ domains and the formation of protein networks at the plasma membrane. Curr Top Microbiol Immunol 228:209-233.

Fiore F, Zambrano N, Minopoli G, Donini V, Duilio A, Russo T (1996) The regions of the Fe65 protein homologous to the phosphotyrosine interaction/phosphotyrosine binding domain of Shc bind the intracellular domain of the Alzheimer's amyloid precursor protein. J Biol Chem 270:30853-30856.

Goldberg J, Nairn AC, Kuriyan J (1996) Structural basis for the autoinhibition of calcium/calmodulin-dependent protein kinase I. Cell 84:875-887.

Guenette SY, Chen J, Jondro PD, Tanzi RE (1996) Association of a novel human FE65-like protein with the cytoplasmic domain of the $\beta$-amyloid precursor protein. Proc Natl Acad Sci USA 93:10832-10837.

Hata Y, Slaughter CA, Sudhof TC (1993) Synaptic vesicle fusion complex contains unc-18 homologue bound to syntaxin. Nature 366:347-351.

Hata Y, Butz S, Sudhof TC (1996) CASK: a novel dlg/PSD95 homolog with an N-terminal calmodulin-dependent protein kinase domain identified by interaction with neurexins. J Neurosci 16:2488-2494.

Hirao K, Hata Y, Ide N, Takeuchi M, Irie M, Yao I, Deguchi M, Toyoda A, Sudhof TC, Takai Y (1998) A novel multiple PDZ domaincontaining molecule interacting with $N$-methyl-D-aspartate receptors and neuronal cell adhesion proteins. J Biol Chem 273:21105-21110.

Hoskins R, Hajnal A, Harp S, Kim S (1996) The C. elegans vulval induction gene lin-2 encodes a member of the MAGUK family of cell junction proteins. Development 122:97-111.

Hsueh Y-P, Yang F-C, Kharazia V, Naisbitt S, Cohen AR, Weinberg RJ, Sheng M (1998) Direct interaction of CASK/LIN-2 and syndecan heparan sulfate proteoglycan and their overlapping distribution in neuronal synapses. J Cell Biol 142:139-151.

James P, Vorherr T, Carafoli E (1995) Calmodulin-binding domains: just two-faced or multi-faced? Trends Biochem Sci 20:38-42.

Kaech SM, Whitfield CW, Kim SK (1998) The LIN-2/LIN-7/LIN-10 complex mediates basolateral membrane localization of the C. elegans EGF receptor LET-23 in vulval epithelial cells. Cell 94:761-771.

Kim E, Niethammer M, Rothschild A, Jan YN, Sheng M (1995) Clus- 
tering of Shaker-type $\mathrm{K}^{+}$channels by interaction with a family of membrane-associated guanylate kinases. Nature 378:85-88.

Kim E, Naisbitt S, Hsueh Y-P, Rao A, Rothschild A, Craig AM, Sheng M (1997) GKAP, a novel synaptic protein that interacts with the guanylate kinase-like domain of the PSD-95/SAP90 family of channel clustering molecules. J Cell Biol 136:669-678.

Kornau H-C, Schenker LT, Kennedy MB, Seeburg PH (1995) Domain interaction between NMDA receptor subunits and the postsynaptic density protein PSD-95. Science 269:1737-1740.

Linstedt AD, Hausi H-P (1993) Giantin, a novel conserved golgi membrane protein containing a cytoplasmic domain of at least $350 \mathrm{kDa}$. Mol Biol Cell 4:679-693.

Lõpez-Figueroa MO, Ravault JP, Cozzi B, Moller M (1996) Presence of nitric oxide synthase in the sheep pineal gland: an experimental immunohistochemical study. Neuroendocrinology 63:384-392.

Lõpez-Figueroa MO, Itoi K, Watson SJ (1998) Regulation of nitric oxide synthase mRNA expression in the rat hippocampus by glucocorticoids. Neuroscience 87:439-446.

McLoughlin DM, Miller CCJ (1996) The intracellular cytoplasmic domain of the Alzheimer's disease amyloid precursor protein interacts with phosphotyrosine-binding domain proteins in the yeast two-hybrid system. FEBS Lett 397:197-200.

Okamoto M, Sudhof TC (1997) Mints, Munc18-interacting proteins in synaptic vesicle exocytosis. J Biol Chem 272:31459-31464.
Pawson T, Scott JD (1997) Signaling through scaffold, anchoring, and adaptor proteins. Science 278:2075-2080.

Pleasure SJ, Lee VM (1993) NTera 2 cells: a human cell line which displays characteristics expected of a human committed neuronal progenitor cell. J Neurosci Res 35:585-602.

Rongo C, Whitfield CW, Rodal A, Kim SK, Kaplan JM (1998) LIN-10 is a shared component of the polarized protein localization pathways in neurons and epithelia. Cell 94:751-759.

Simske JS, Kaech SM, Harp SA, Kim SK (1996) LET-23 receptor localization by the cell junction protein LIN-7 during C. elegans vulval induction. Cell 85:195-204.

Trommsdorff M, Borg J, Margolis B, Herz J (1998) Interaction of cytosolic adaptor proteins with neuronal apolipoprotein $\mathrm{E}$ receptors and the amyloid precursor protein. J Biol Chem 273:33556-33565.

Wyszynski M, Lin J, Rao A, Nigh E, Beggs AH, Craig AM, Sheng M (1997) Competitive binding of $\alpha$-actinin and calmodulin to the NMDA receptor. Nature 385:439-442.

Xu X-Z, Choudhury A, Li X, Montell C (1998) Coordination of an array of signaling proteins through homo- and heteromeric interactions between PDZ domains and target proteins. J Cell Biol 142:545-555.

Zhang Z, Lee CH, Mandiyan V, Borg J-P, Margolis B, Schlessinger J, Kuriyan J (1997) Sequence-specific recognition of the internalization motif of the Alzheimer's amyloid precursor protein by the X11 PTB domain. EMBO J 16:6141-6150. 